\title{
Neuropeptides (Substance P) Localisation in the Peripheral Nervous System and Skin in a Diabetic Rat Model: A Possible Mechanism for Acceleration Wound Healing in Diabetic Rats
}

Seham A Abd El-Aleem ${ }^{* 1}$ and Edward B Jude ${ }^{2}$

${ }^{1}$ Department of Histology, Minia Faculty of Medicine, Minia University, Egypt

${ }^{2}$ Diabetes Centre, Tameside Hospital NHS Foundation Trust and University of Manchester, Lancashire, UK

*Corresponding author: Abd El-Aleem SA, Department of Histology, Minia Faculty of Medicine, Minia University, Egypt, Tel: +201002997270; E-mail: Seham.abdelaleem@minia.edu.eg

Received date: July 04, 2018; Accepted date: July 12, 2018; Published date: July 18, 2018

Copyright: (c) 2018 Abd El-Aleem SA, et al. This is an open-access article distributed under the terms of the Creative Commons Attribution License, which permits unrestricted use, distribution, and reproduction in any medium, provided the original author and source are credited.

\begin{abstract}
Background: Diabetes is a metabolic disorder associated with biochemical and neurochemical changes in the tissues. Diabetic neuropathy is attributed to the neurochemical changes and is the underlying cause of the impaired diabetic wound healing. Substance $\mathrm{P}$, a neuropeptide functions as a mediator of local inflammatory responses.
\end{abstract}

Aims: To study the expression of substance $P$ in the peripheral nervous system and in the skin in a diabetic rat model. Additionally, to study the effect of the topical application of substance P on the diabetic wound healing and scarring.

Materials and Methods: Streptozotocin-induced diabetic rat model was used. Immunostaining was used to study the expression of substance $P$, in the peripheral nervous system and in the skin from normal and diabetic unwounded rats. Diabetic wound model was obtained by creating four incisional wounds at the back of the rats. Two wounds were treated by topical application of substance $\mathrm{P}$ daily for two weeks and two wounds served as controls. The tissues were harvested two, four and eight weeks postwounding. Macrophage invasion and inducible nitric oxide synthase level (iNOS) were assessed by immunocytochemistry. Postwounding scarring was assessed by Masson Trichrome.

Results: Substance P was expressed in the dorsal root ganglia, in the spinal nerves and peripheral dermal nerves both in the diabetic and non-diabetic animals. However, the diabetic rat nerves showed downregulation of substance $P$ and degenerative changes. Diabetic skin showed a significant $(P<0.02)$ downregulation of substance $P$. Treatment by substance $P$ promoted healing, reduced inflammation and significantly reduced wound macrophage invasion $(P<0.007)$ and iNOS levels $(P<0.02)$. Interestingly, Substance $P$ improved the scar quality and reduced wound width significantly four $(P<0.05)$ and eight $(P<0.03)$ weeks postwounding.

Conclusion: This diabetic model was associated with neuropathic changes. Downregulation of substance $\mathrm{P}$ in the diabetic nerves could be contributing to the development of diabetic neuropathy and delayed wound healing. Topical application of substance $P$ to the wounds can accelerate the healing, probably through enhancing the vasculature of the skin and relieving diabetic neuropathy. This could provide a new line of treatment for surgical diabetic wounds to achieve early healing with minimal scars.

Keywords: Diabetes; Wound healing; Diabetic wound healing; Inflammation; Substance P; Neuropeptides

\section{Introduction}

\section{Diabetes and wound healing}

Impairment of diabetic wound healing is a major health problem causing elevated hospital costs and poor quality of life for patients [1-3]. Wound healing is an organised multiphase process [4-6] with overlapping events; inflammation, reepithelialisation, angiogenesis, collagen deposition and tissue remodelling [7]. These phases are regulated by coordinated interaction between keratinocytes endothelial cells, fibroblasts, macrophages at the wound site [7-9] and cells infiltrating the wound [8]. These cells produce a plethora of biological mediators at the wound site [9] that regulate different phases of healing. Therefore, wound cells are the main players in the healing process and their activities are regulated through paracrine and autocrine routes by the biological mediators they produce locally.

\section{Diabetic wounds and neuropeptides}

The metabolic disorder associated with diabetes affects the cellular and biochemical components of wound healing. This results in dysregulation of the phases of healing with subsequent impairment of healing $[10,11]$. Several studies considered the regulation and the role of different biological/biochemical mediators in wound healing $[11,12]$. In the last two decades, attention has been given to the contribution of the neuronal mediators to the wound healing $[13,14]$. The nervous system responds to tissue injury by releasing neuronal 
Citation: Abd El-Aleem SA, Jude EB (2018) Neuropeptides (Substance P) Localisation in the Peripheral Nervous System and Skin in a Diabetic Rat Model: A Possible Mechanism for Acceleration Wound Healing in Diabetic Rats. J Cytol Histol 9: 510. doi: 10.4172/2157-7099.1000510

Page 2 of 12

mediators, neuropeptides such as substance $\mathrm{P}$ from the nerve ending at the site of injury $[15,16]$. In diabetes, the reduction in NPs in nerves contributes to the development of diabetic neuropathy and the associated vascular disorder which are believed to contribute to the delayed wound healing [17-22]. Substance P is a neurotransmitter produced in nerve cell body and transmitted along the nerve axon to be released at the nerve endings [23,24]. It has a diversity of effects on different cell population; keratinocyte, endothelial cells, lymphocytes and fibroblast $[25,26]$. It has a complex role in inflammation and tissue trauma [27-29]. Substance P is upregulated in wound [30-32] but is reduced in diabetic wound [33] and it was hypothesized that healing can be promoted by substance $P$ treatment $[18,34-36]$, but the exact mechanism is not fully understood.

Hypothesis: We hypothesise that the neurochemical changes associated with diabetes contribute to the development of diabetic neuropathy and contribute to the impairment of wound healing. Therefore, we used a diabetic wound model in which there is a combination of neuronal disorder and mechanical damage of the tissue and nerve by wounding. This provides a good model to study the contribution of the nervous system to the healing. We study the neuronal histochemical changes in the peripheral nervous system in an animal model of diabetes. Additionally, we study the effect of the topical application of the neuropeptide substance $\mathrm{P}$ to diabetic wounds on the healing course and the postwounding scar.

\section{Materials and Methods}

\section{Diabetic model}

Adult male Sprague Dawley rats, 225 to $250 \mathrm{~g}$, age and weight matched, (5 per group) were housed singly and a standard rat diet and water were allowed for a week prior to the experiment. Diabetes model was established. Briefly, after sixteen hours fasting a single dose (65 $\mathrm{mg} / \mathrm{kg}$ ) of streptozotocin (Sigma) dissolved in a solution of $0.1 \mathrm{M}$ citric acid buffer ( $\mathrm{pH}$ 4.5), was injected intraperitoneally. Rats were monitored 48 hours later by measuring urine glucose and blood glucose levels once weekly for three weeks. The rats were considered diabetic when they have three consecutive positive urine glucose and blood glucose concentration higher than $16.7 \mathrm{mM}$.

\section{Animal grouping}

The animals were grouped into; unwounded groups including nondiabetic group (5 rats) and diabetic group (5 rats) to study substance $\mathrm{P}$ localization in the neurons and in the unwounded skin. The diabetic wounded group including two, four and eight weeks wounded groups (5 rats per time point) to study the effect of substance $\mathrm{P}$ topical application on the wound healing.

\section{Incisional wounds}

Eight weeks after induction of diabetes, four full-thickness incisions $1 \mathrm{~cm}$ each was made at the back of the animals under halothane anaesthesia. The left two wounds were treated with substance $P$ and the right two wound were treated with saline (control diabetic wounds). A drop $(50 \mu \mathrm{l})$ of normal saline was applied to the control wound followed by a layer of Aquaphor to cover the wound. A drop (50 $\mu \mathrm{l})$ ) of $(0.5 \mathrm{mg} / \mathrm{ml})$ substance $\mathrm{P}$ (Sigma) solution was applied followed by a layer of $0.05 \%(0.5 \mathrm{mg} / \mathrm{g})$ substance P-Aquaphor to cover the wound. The treatment was applied topically to the wounds once daily for two weeks. The wounds were un-sutured and allowed to heal by secondary intention. The animals were housed in individual cages and allowed to recover. Animals were kept under the same conditions until the end of the experiment. The wounded animals were sacrificed two, four and eight weeks post-wounding to study the resolution of inflammation, wound remodeling and the scarring.

\section{Photographing the wounds}

Following the surgery, the wounds were examined regularly to follow the rate of wound contraction and closure. The wounds were photographed 1,3,7 and 14 days post-wounding. The two weeks wounds were photographed from the dermal surface after harvesting the wounds to show the wound vascularity. The scars were photographed eight weeks post-wounding prior to rat scarification.

\section{Animal scarification and tissue harvesting}

Animals were sacrificed two, four and eight weeks post-wounding by chloroform overdose followed by cervical dislocation. For the wounded groups, the dorsal skin was removed using a sterile surgical blade down to and including the panniculus carnosus muscle. The entire wound plus a $1 \mathrm{~mm}$ margin of normal skin from each of the treated and control diabetic wound sites on each animal was excised and preserved. One wound was preserved in $10 \%$ formal saline for histological and histochemical staining and the other wound was kept in $-20^{\circ} \mathrm{C}$. Wounds for paraffin embedding were dissected, fixed in $10 \%$ formalin for 48 hours and processed in the automated machine. Paraffin blocks were sectioned at 5 microns thickness on poly L lysine coated slides and used for the staining. Sampling of the wounds was standardized by selecting at least 3 sections from identical sites within the wounds for each staining. The unwounded, control and diabetic animals were sacrificed and the dorsal skin, thoracic spinal dorsal root ganglia and nerves were harvested. The skin was fixed for paraffin embedding as above and the dorsal root ganglia and nerves were embedded in OCT for sectioning by cryostat. OCT blocks were sectioned at 10 microns thickness on poly $\mathrm{L}$ lysine coated slides and kept in $-20^{\circ} \mathrm{C}$ for immunostaining.

\section{Immunohistochemical staining for localization of substance $P$ in neurons}

Cryosections of the ganglia and nerves were rinsed briefly in TBS. Endogenous peroxidases were blocked by treatment with $0.5 \%$ hydrogen peroxide $\left(\mathrm{H}_{2} \mathrm{O}_{2}\right)$ in methanol. Sections were incubated in the diluted primary antibody (substance P 1:500) overnight at $4^{\circ} \mathrm{C}$. The staining was completed using Novolink kits (Leica Novolink Polymer Detection System, Catalogue number: RE7150-K) and reagents were prepared and used according to the manufacturer's instructions. Briefly, sections were incubated with post-primary (30 minutes at room temperature) followed by polymer (30 minutes at room temperature). Reactions were developed with 3.3' diaminobenzidine substrate (Sigma) dissolved in distilled water for the appropriate period. Sections were then counterstained with haematoxylin and dehydrated prior to mounting with DPX and cover-slipped for microscopic examination. Negative control in which primary antibodies were replaced with normal serum of the host species of the secondary antibody was used with each run. Positive signals appear as brown staining on the sections with the counterstaining in blue. Specimens were viewed using a Leica DRRB microscope and images were captured using a Spot RT Slider digital camera (Image Solutions) using Spot RT software run on a PC. 
Citation: Abd El-Aleem SA, Jude EB (2018) Neuropeptides (Substance P) Localisation in the Peripheral Nervous System and Skin in a Diabetic Rat Model: A Possible Mechanism for Acceleration Wound Healing in Diabetic Rats. J Cytol Histol 9: 510. doi: $10.4172 / 2157-7099.1000510$

Page 3 of 12

\section{Immunofluorescent staining for detection of substance $P$, iNOS and macrophages in the skin}

Paraffin sections were dewaxed in xylene and hydrated through alcohol gradient. Antigen retrieval was performed in $0.01 \mathrm{M}$ sodium citrate buffer ( $\mathrm{pH} \mathrm{6)}$ for 20 minutes in a microwave at 750. Sections were incubated with the primary antibody of interest (substance $\mathrm{P}$ 1:200, iNOS 1:1000, CD68 1:500) overnight at $4^{\circ} \mathrm{C}$. Sections were washed in TBS and incubated for one hour at room temperature with the appropriate conjugated secondary antibody (TRITC conjugated for substance $\mathrm{P}$ and CD68 and FITC conjugated for iNOS) diluted 1:100 in TBS. For colocalising iNOS and CD68; the sections were stained for iNOS as above, then sections were incubated with CD68 antibody (1:500) for one hour at room temperature. Then sections were washed and incubated for a further 30 minutes with a biotinylated secondary antibody (1:500) and then with streptavidin-fluorescein (Amersham Pharmacia Biotech, Buckinghamshire, UK), 1:100, in TBS for one hour at room temperature. Sections were then mounted in polyvinyl alcohol. Viewed using the Leica DMRB microscope operating in fluorescence mode with appropriate filter sets and images were captured.

Primary antibodies used: Substance P: Polyclonal Rabbit AntiSubstance P antibody (ABCAM, ab216412). iNOS: Polyclonal Rabbit Anti-iNOS/NOS Type II (BD Transduction Laboratories, 610332). Macrophage Marker: CD68 mouse monoclonal antibody (Dako, M0814).

\section{Masson's Trichrome staining for collagen and post-wounding scar assessment}

Sections were stained with Masson's Trichrome to examine the dermal connective tissue. Sections were dewaxed, rehydrated and processed for the staining, distilled water was used for washing through all the procedure. Sections were incubated in Harris' Haematoxylin for three minutes and left in running water for two minutes. The stained in picric acid for one minute followed one minute washing. Then stained with $25 \%$ Biebrisch scarlet for one minute with one minute washing, sections were then stained with phosphotungstic/ phosphomolybdic acid solution for three minutes, and then stained in fast green for ten minutes. Slides were dehydrated and mounted in Pertex mounting media and images were captured with bright field as above.

\section{Assessment of immunoreactivities}

Image J software (developed at US National Institutes of Health) was used to assess substance P, iNOS and CD68 immunoreactivities on immunofluorescence stained slides in the field of a $20 \mathrm{X}$ objective. The immunoreactivity was assessed by measuring the surface area covered by the positive staining. In each animal, 3 sections were scored and the distance between sections was $50 \mathrm{~mm}$. Before starting the analysis, the setting was adjusted on a test slide for each primary antibody and the same setting parameters were used throughout the whole experiment on all slides.

\section{Wound width measurement}

Using image analysis software, the slides stained with Masson Trichrome were used to measure the wound width four and eight weeks postwounding. The distances from the right side of the wound to the left side just under the epithelium was measured. The wound width measurements were performed on three sections from the wound cut 500 microns apart.

\section{Statistics}

Statistical analyses were performed using IBM SPSS statistical package. Results were expressed as the mean \pm SEM. Expression data were compared using Mann-Whitney $\mathrm{U}$ test comparing the expression levels in each experimental group to those in the corresponding control groups, with $\mathrm{P}<0.05$ being considered as statistically significant.

\section{Results}

\section{Expression of substance $P$ in the ganglia and nerves from diabetic and non-diabetic rats}

Immunostaining of the dorsal root ganglia showed substance $\mathrm{P}$ expression in small size primary afferent neurons both in the diabetic (Figure 1B) and non-diabetic (Figure 1A) rats. Spinal nerves showed substance $\mathrm{P}$ immunoreactivity both in the diabetic (Figure $1 \mathrm{D}$ and $1 \mathrm{~F}$ ) and the non-diabetic (Figure $1 \mathrm{C}$ and $1 \mathrm{E}$ ) rats. Non-diabetic nerves showed dense immunoreactivity and wide distribution in almost all the axons within the nerve (Figure $1 \mathrm{C}$ and $1 \mathrm{E}$ ). However, the diabetic nerves exhibited reduced immunoreactivity in the term of staining density and distribution (Figure $1 \mathrm{D}$ and $1 \mathrm{~F}$ ). Interestingly, spinal nerves from the diabetic rats showed variable degree of degenerative changes (Figure 1D and $1 \mathrm{~F}$ ) by comparison to nerves from nondiabetic (Figure $1 \mathrm{C}$ and $1 \mathrm{E}$ ). The degenerative changes mostly seen are axonal atrophy, beading, cytoplasmic vacuolations and axonal demyelination with increase inter-axonal spaces (Figure 1D and $1 \mathrm{~F}$ ).

\section{Expression of substance $P$ in the skin from diabetic and non- diabetic rats}

Substance P immunoreactivity was seen in the dermis both in the diabetic and non-diabetic animals (Figure 2). The expression was mainly in the dermal nerve fibres (Figure $2 \mathrm{~A}$ and $2 \mathrm{~B}$ ). Image $\mathrm{J}$ analysis demonstrated that the diabetic skin has a significant $(\mathrm{P}<0.004)$ reduction in substance $\mathrm{P}$ expression by comparison to the non-diabetic skin (Figure 2C).

\section{Effect of substance $P$ application on the diabetic wound healing macroscopically}

Gross examination of the wounds showed that both the control and the treated diabetic wounds exhibited signs of inflammation at early stages (Figure 3A-3C). The treated wounds showed signs of healing, resolution of inflammation and wound contraction by day 14 (Figure 3D). However, the control diabetic wounds showed delayed healing, persistence inflammation and delayed wound contraction (Figure 3D). Examination of the visceral side of the wounds three weeks postwounding, showed increase in the vascularity with newly formed blood vessels seen growing toward the wound site in the treated group (Figure 3F) but not in the control diabetic wounds (Figure 3E). Wound closure was complete with formation of scar tissue four weeks postwounding in both the control and the treated diabetic wounds. Eight weeks postwounding there was remarkable improvement in the post-wounding scar quality in the treated groups (Figure $3 \mathrm{G}$ and $3 \mathrm{H}$ ). 
Citation: Abd El-Aleem SA, Jude EB (2018) Neuropeptides (Substance P) Localisation in the Peripheral Nervous System and Skin in a Diabetic Rat Model: A Possible Mechanism for Acceleration Wound Healing in Diabetic Rats. J Cytol Histol 9: 510. doi: $10.4172 / 2157-7099.1000510$

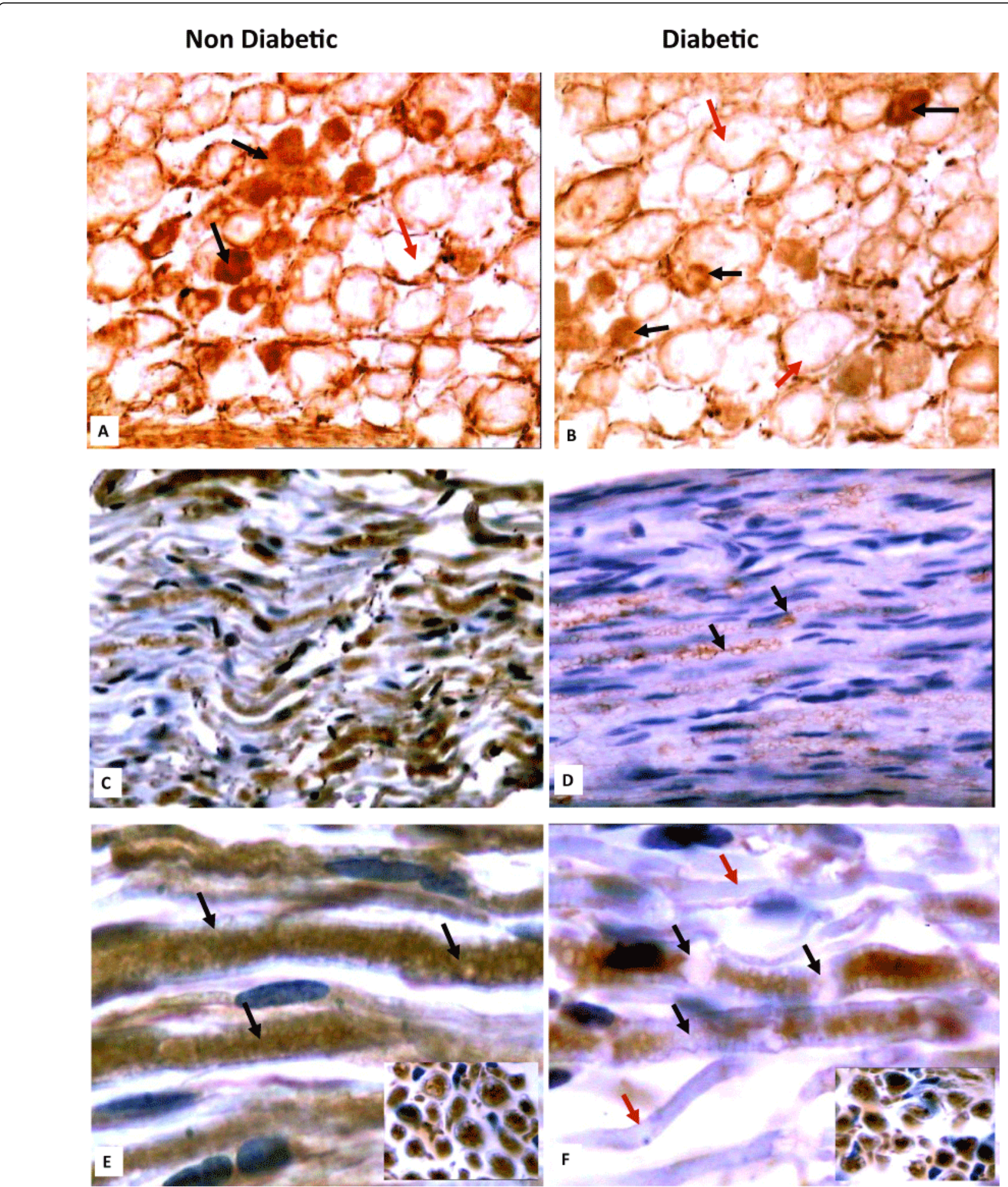

Figure 1: A representative photomicrograph showing the localisation of substance $\mathrm{P}$ in the dorsal root ganglia $(\mathrm{A}, \mathrm{B})$ and in the spinal nerves (C-F) from non-diabetic (A, C, E) and diabetic animals (B, D, F). A, B) Dorsal root ganglia showing localisation of substance $\mathrm{P}$ in the small size primary neurons (black arrows) but not in the large size neurons (red arrows). C, E) Non-diabetic nerve showing dense immunoreactivity filling the axoplasm (black arrows). D, F) Diabetic nerves showing degenerative changes (Black arrows), demyelination (red arrows) and apparent reduction in substance $\mathrm{P}$ immunoreactivity. The inserts in $\mathrm{E}, \mathrm{F}$ are transverse sections of the nerves. Notice the increased spaces between axons in the diabetic nerve (insert in $\mathrm{F}$ ) due to the degenerative neuropathic changes by comparison to the control diabetic nerves (insert in $\mathrm{E}$ ). $\mathrm{A}, \mathrm{B})=\mathrm{X} 40, \mathrm{C}, \mathrm{D}=\mathrm{X} 20$; $\mathrm{E}, \mathrm{F}=\mathrm{X} 100$. 
Citation: Abd El-Aleem SA, Jude EB (2018) Neuropeptides (Substance P) Localisation in the Peripheral Nervous System and Skin in a Diabetic Rat Model: A Possible Mechanism for Acceleration Wound Healing in Diabetic Rats. J Cytol Histol 9: 510. doi: 10.4172/2157-7099.1000510

Page 5 of 12

Therefore, macroscopic examination showed that substance P effect was most prominent two weeks postwounding with reduction of inflammation and enhancement of early wound contraction (Figure 3D). Thus, this time point was considered as the time of resolution of inflammation and beginning of wound remodelling. To study the effect of substance $\mathrm{P}$ on the delayed inflammation in the diabetic groups, two weeks wounds were evaluated microscopically by assessment of the wound macrophages and wound iNOS using immunostaining and image analysis for quantification.

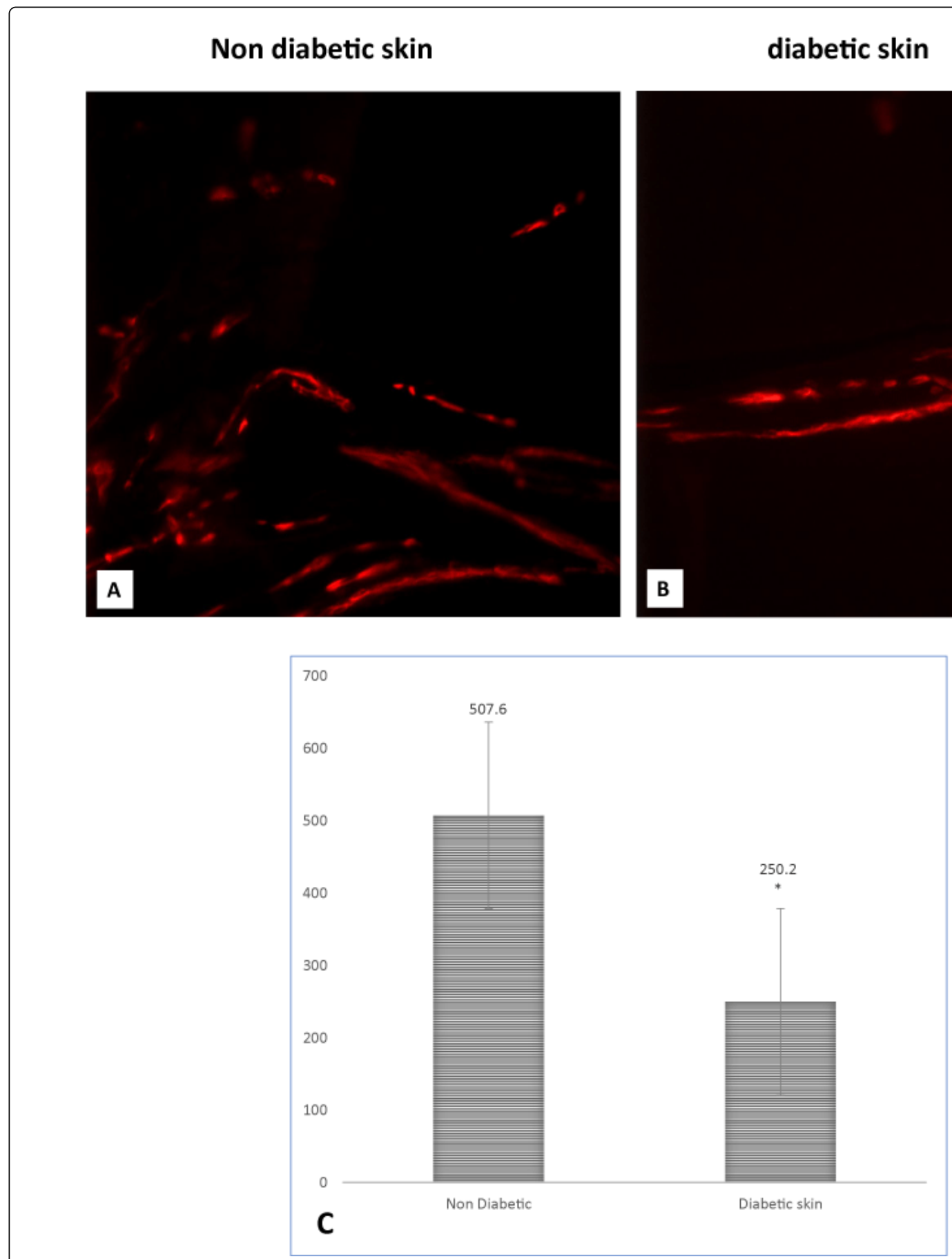

Figure 2: A representative photomicrograph showing the expression of substance $\mathrm{P}$ in the control non-diabetic (A) and in the diabetic (B) rat skin. Immunoreactivity is seen in the dermal nerves both in the diabetic (B) and non-diabetic skin (A) and in few dermal cells in the diabetic skin. C) A graph showing that the level of substance $\mathrm{P}$ is significantly $(\mathrm{P}<0.02)$ downregulated in diabetic skin by comparison to the nondiabetic skin. 
Citation: Abd El-Aleem SA, Jude EB (2018) Neuropeptides (Substance P) Localisation in the Peripheral Nervous System and Skin in a Diabetic Rat Model: A Possible Mechanism for Acceleration Wound Healing in Diabetic Rats. J Cytol Histol 9: 510. doi: 10.4172/2157-7099.1000510

Page 6 of 12

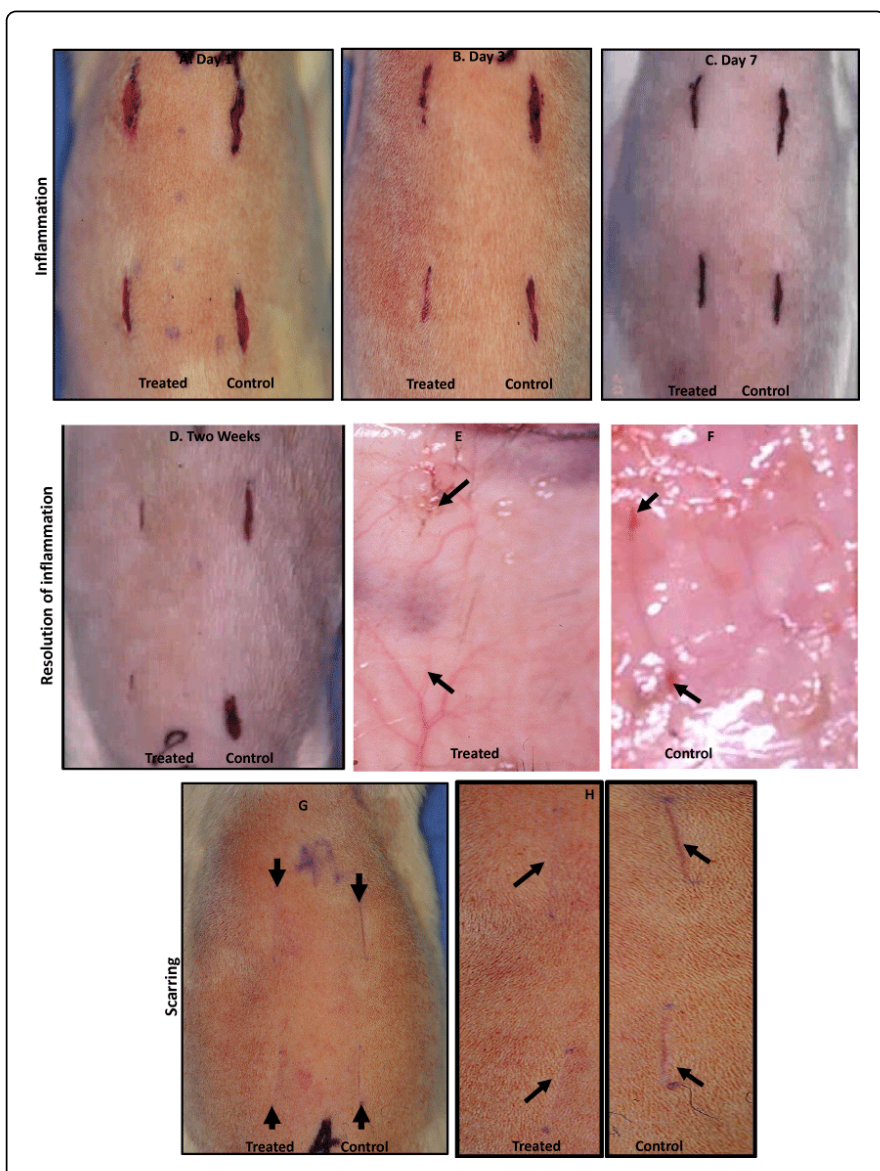

Figure 3: A representative photograph showing macroscopic appearance of the wound and scars in diabetic wounds at different time points: A-C) At early time points 1,3 and 7 days postwounding (A-C) congestion, inflammation and scab formation are seen both in the control diabetic and the treated wounds. D) Two weeks post-wounding, the control diabetic wounds show open wounds, inflammation and congestion. In contrast, substance $\mathrm{P}$ treated wounds show markedly improved healing with wound contraction, less congestion and less inflammation indicating the resolution of inflammation now point. E, F) Two weeks wounds seen from the dermal surface, the rostal and caudal ends of the wound indicated by (arrows). The treated wounds (E) show blood vessels sprouting from the rostal and the caudal ends of the wound toward the centre. G, H) Eight weeks post-wounding, substance $P$ treated wounds show remarkable improvement in the formed scar (arrows) which is not distinguishable from the adjacent unwounded skin. H) A higher magnification showing that the control diabetic wounds healed by scars (arrows) which are deep and clearly distinguishable from the adjacent skin, however the treated diabetic wounds healed by scars (arrows) which are indistinguishable from the surrounding skin.

\section{Effect of substance $P$ application on wound inflammation two weeks post-wounding}

Immunostaining showed infiltration of both the control and the treated diabetic wounds by macrophages (Figure $4 \mathrm{~A}$ and $4 \mathrm{~B}$ ) and showed expression of iNOS in the wound site (Figures 4C, 4D, 5A and $5 B)$. Substance $P$ treated wounds exhibited a significant reduction in the wound macrophage $(\mathrm{P}<0.007)$ and wound iNOS $(\mathrm{P}<0.02)$ immunoreactivities by comparison to the control diabetic wounds (Figure 5C). Interestingly double immunofluorescent showed that most of the macrophages at the wound site expressed iNOS (Figure $4 \mathrm{E}$ and $4 \mathrm{~F}$ ). iNOS was widely distributed in the control (Figure $5 \mathrm{~A}$ ) by comparison to the treated diabetic wounds (Figure 5B). The main cellular source was vascular endothelial lining and inflammatory cells infiltrating the wound (Figure 5A and 5B). Substance $\mathrm{P}$ local application to the wound reduced the production of wound iNOS probably by reducing the infiltrating inflammatory cells (Figure 5). The main cellular source of iNOS in the control diabetic wounds was the infiltrating inflammatory cells (Figure $5 \mathrm{~A}$ ), but in substance $\mathrm{P}$ treated wound was the vascular endothelial cells (Figure 5B). Interestingly, photographic images of the dermal surfaces of the wounds showed increased vascularity and angiogenesis of the treated wound (Figure $3 \mathrm{E}$ ) by comparison to the control diabetic wounds (Figure 3F). Therefore, delayed inflammation in the control diabetic wounds is associated with increase in macrophages infiltration and iNOS production. Substance $\mathrm{P}$ treatment reduced macrophages infiltration of the wound and subsequently reduced wound iNOS production.

\section{Effect of substance $P$ on wound remodeling and scarring four and eight weeks post-wounding}

Masson's Trichrome was used to assess the wound remodelling and the dermal architecture four and eight weeks post-wounding to evaluate the effect of exogenous substance $\mathrm{P}$ on the scar quality. The main criteria considered for assessing scar quality was; the stretch of the epithelium overlying the scars, collagen fibres organisation, orientation and spacing in between. Image J was used to measure the wound width.

Control diabetic wounds: Showed a well-defined scar tissue in the wound gap four (Figure 6A) and eight weeks (Figure 6B) postwounding. The epithelium overlaying the scar was stretched. The dermal architecture in the scar tissues was distinct from the adjacent unwounded dermis. The collagen forming the scar showed lack of spaces between the collagen fibres and between the collagen bundles. Eight weeks post-wounding, the epithelium overlaying the scar was less stretched and the collagen deposited compactly in an abnormal pattern with obliteration of spaces in between (Figure 6B).

Substance P treated wounds: Four weeks scar showed spacing between collagen bundles and between collagen fibres (Figure 6C). The epithelium overlaying the scar was less stretched and shows a wavy appearance. The dermal architecture in the scar tissues was slightly distinct from the adjacent unwounded dermis. There was an apparent increase in the vascularity in the wound gap and in the adjacent dermis. Spaces between collagen bundles were filled with the newly formed blood vessels (Figure 6C). Eight weeks scar showed marked improvement in the quality of the postwounding scar. Collagen fibres were deposited in a reticular network resembling the dermal architecture of the adjacent unwounded dermis (Figure 6D). 
Citation: Abd El-Aleem SA, Jude EB (2018) Neuropeptides (Substance P) Localisation in the Peripheral Nervous System and Skin in a Diabetic Rat Model: A Possible Mechanism for Acceleration Wound Healing in Diabetic Rats. J Cytol Histol 9: 510. doi: 10.4172/2157-7099.1000510

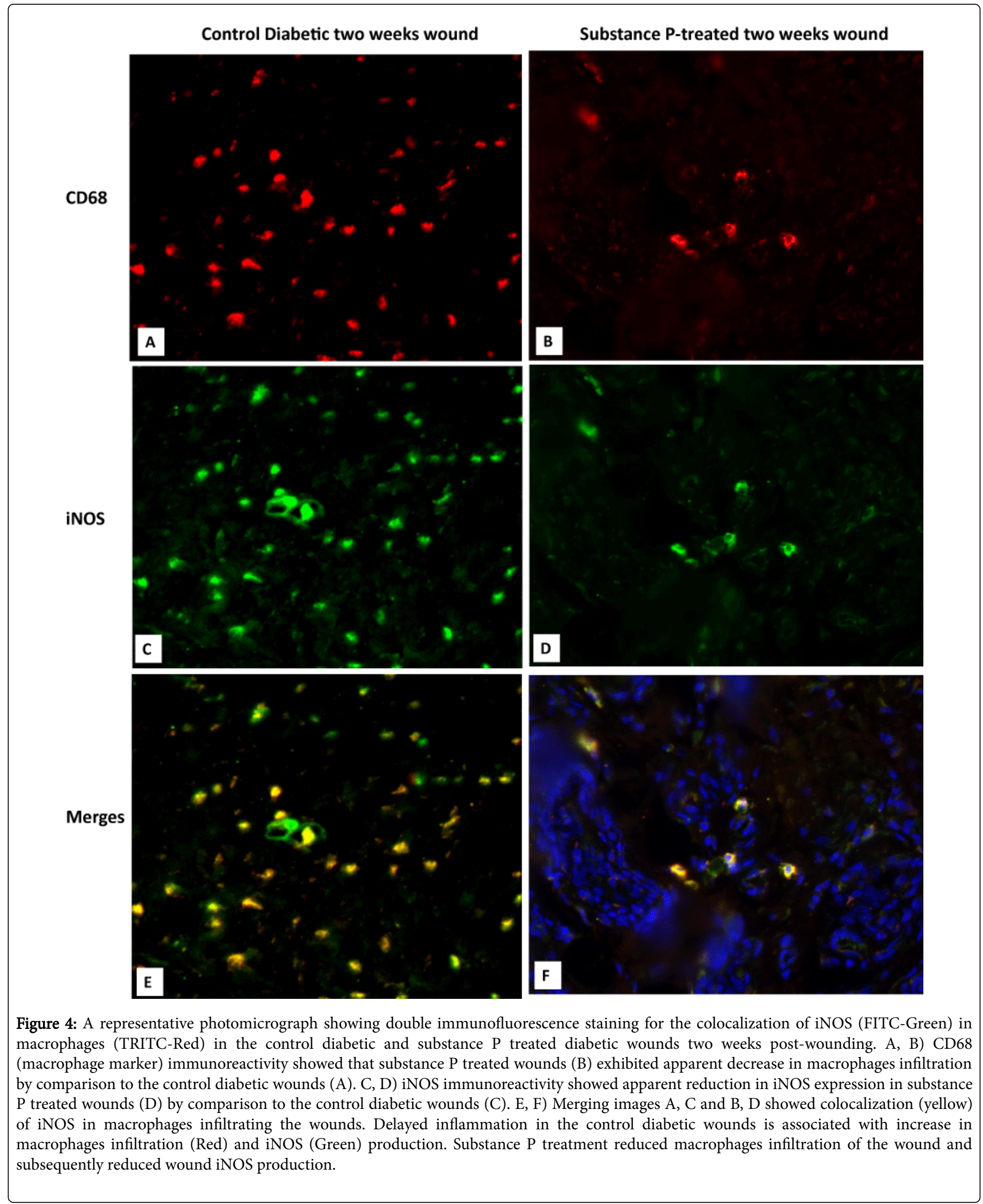


Citation: Abd El-Aleem SA, Jude EB (2018) Neuropeptides (Substance P) Localisation in the Peripheral Nervous System and Skin in a Diabetic Rat Model: A Possible Mechanism for Acceleration Wound Healing in Diabetic Rats. J Cytol Histol 9: 510. doi: 10.4172/2157-7099.1000510

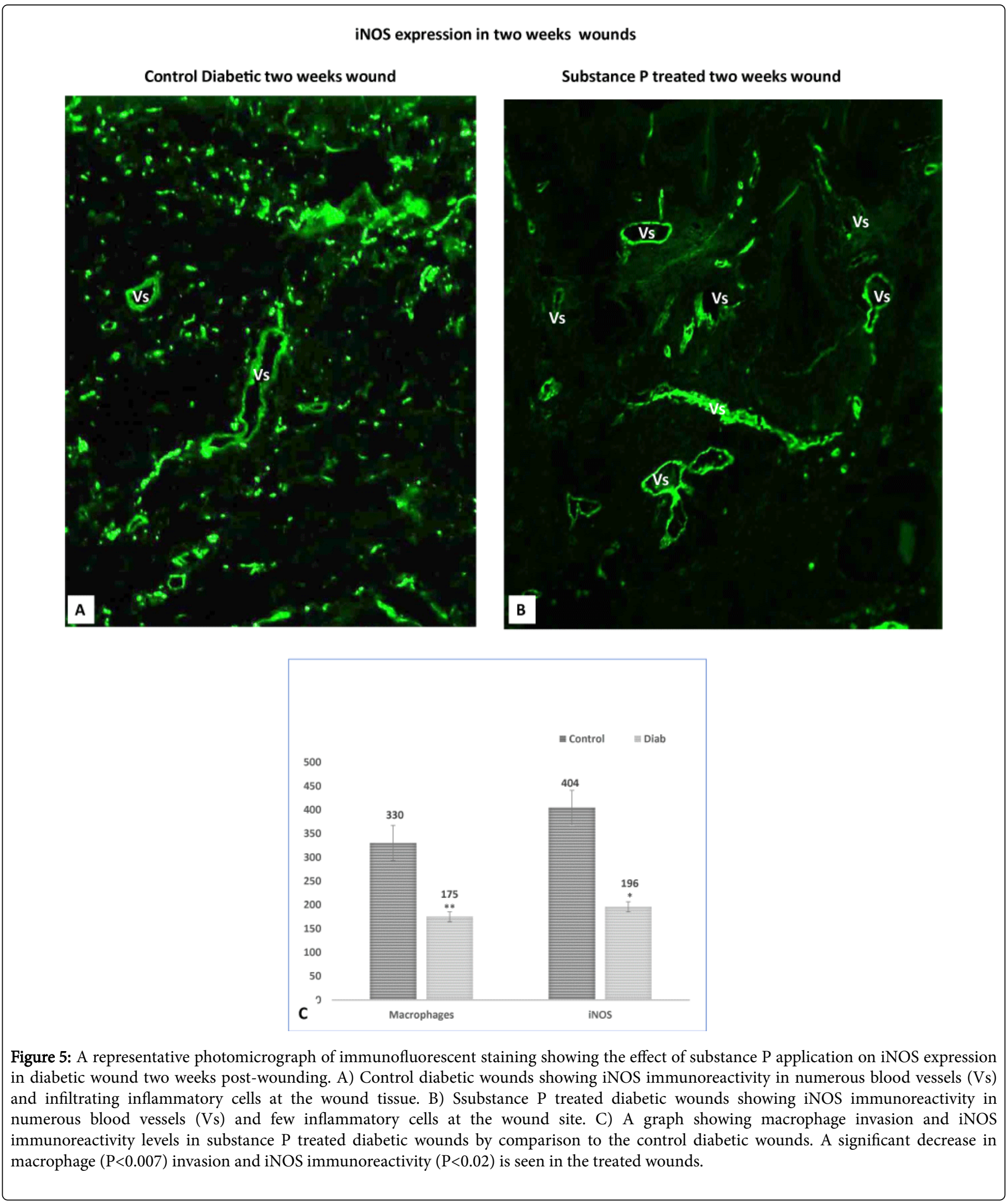


Citation: Abd El-Aleem SA, Jude EB (2018) Neuropeptides (Substance P) Localisation in the Peripheral Nervous System and Skin in a Diabetic Rat Model: A Possible Mechanism for Acceleration Wound Healing in Diabetic Rats. J Cytol Histol 9: 510. doi: $10.4172 / 2157-7099.1000510$

Page 9 of 12

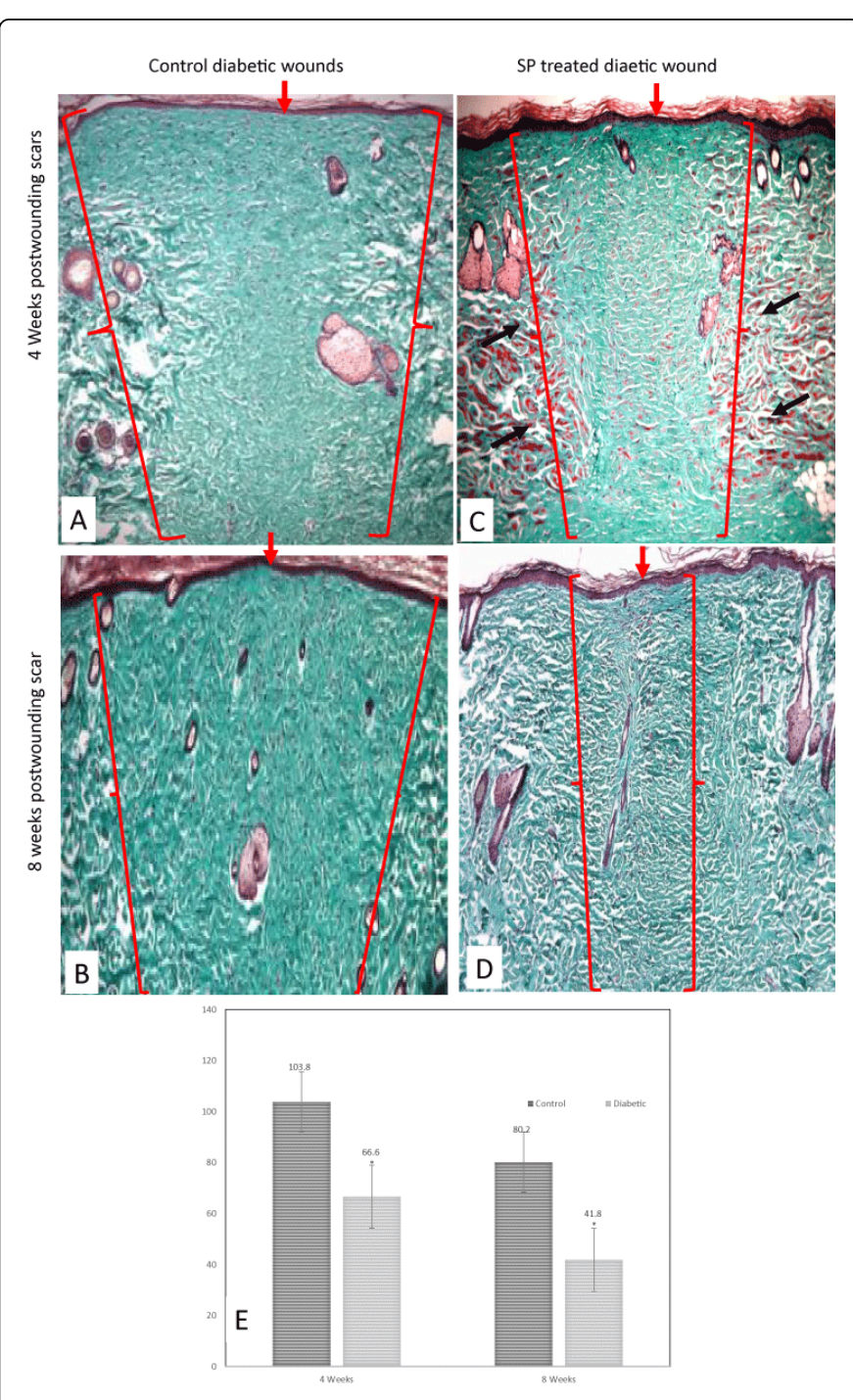

Figure 6: Representative photomicrographs of Masson Trichrome collagen staining showing the effect of substance $\mathrm{P}$ application on the wound gap (between brackets) and the scar formed four and eight weeks post-wounding in diabetic rats. A, B) Control diabetic wounds four (A) and eight (B) weeks postwounding showing a wide wound gap filled up with dense compact collagen bundles with obliteration of the spaces between collagen fibres and between collagen bundles. Re-epithelialisation is a thin stretched layer of epithelium (red arrow). C) Substance P treated wound four weeks postwounding, showing marked reduction in the wound gap and less dense collagen. Re-epithelialisation is a wavy thick layer of epithelium (red arrow). Newly formed blood vessels (angiogenesis) are seen extending from the side of the wound (black arrows) toward the wound gap. D) Substance P treated wound eight weeks postwounding, showing marked reduction in the wound gap. Collagen fibres are arranged in a reticular pattern with spacing in between resembling that of the normal dermis. E) A graph showing the wound width in the control diabetic and substance P treated diabetic wounds four and eight weeks post-wounding. Substance P treated wounds exhibited a significant reduction in the wound width by comparison to the control diabetic wounds four weeks $(\mathrm{P}<0.05)$ and eight weeks $(\mathrm{P}<0.03)$.

\section{Effect of substance $P$ application on wound width four and eight weeks post-wounding}

Substance P treated wounds exhibited a significant reduction in the wound width by comparison to the control diabetic wounds four weeks $(\mathrm{P}<0.05$, Figure $6 \mathrm{E})$ and eight weeks $(\mathrm{P}<0.03$ Figure $6 \mathrm{E})$.

Therefore, the treated wounds showed marked improvement in the postwounding scar which was not distinguished from the adjacent unwounded skin (Figure 6D). In contrast, the control diabetic wounds healed with a prominent, well-defined scar (Figure 6B). Therefore, substance $\mathrm{P}$ promoted wound contraction which healed by narrower scar resembling the dermal architecture of the adjacent unwounded skin.

\section{Discussion and Conclusion}

\section{Loss of nerve integrity and downregulation of substance $P$ in diabetic rats}

We have shown that diabetic nerves exhibited disorganisation, lack of integrity and reduction in substance $\mathrm{P}$ expression. These structural and functional changes could account for the general neuronal phenomena associated with diabetes that affect nerves and cause neuropathy $[37,38]$. Therefore, our diabetic model is associated with neuropathy indicating the success of developing the model. We have shown low production of substance $\mathrm{P}$ in the ganglionic neurons and in the peripheral nerves. The neuropathic changes in diabetic nerves reduce the production of the neurotrophic factors particularly nerve growth factor [17,39-41], this account for the neuronal and axonal deficit with further reduction in substance $P$ secretion in the peripheral nerves. Indeed, this attribute to the reduced levels of substance $P$ in the diabetic skin seen in this study and in other studies [17,39-42]. Here, showing fewer nerves expressing substance $\mathrm{P}$ in the diabetic skin by comparison to control skin indicating the establishment of peripheral neuropathy in our model [33].

\section{Substance $P$ in wound healing}

Under normal condition, tissue injury stimulates the peripheral nerve endings to release neuronal factors which accelerate wound healing [43-48]. The release of substance $P$ from the dermal nerve endings causes an inflammatory response, cellular proliferation and migration to the wound site $[49,50]$. Moreover, substance $\mathrm{P}$ enhances early neurogenic inflammatory reactions, rapidly contracts the initial wound, reduces the wound surface area, and stabilizes the in vivo surroundings. Therefore, the inflammatory and the vascular changes at the wound site are attributed to the release of substance P from the nerve ending [51,52].

In diabetes, the neuropathy and hyperglycaemia affect angiogenesis [53-56] and the vasodilatory response [57]. These restrict inflammatory cell migration and invasion into the wound site and delay onset of inflammatory phase. Therefore, in diabetes lack of neuronal and vascular integrity affect the inflammatory phase leading to the abnormalities in diabetic wound healing $[58,59]$.

It has been demonstrated that peripheral nerves and cutaneous neurobiology contribute to wound healing process [60]. Delayed healing is characterized by chronic inflammation, impaired angiogenesis and decreased collagen production. In diabetic foot ulcer, the loss of peripheral sensory reduces the production of neuropeptides that are important for proper wound healing [61]. Some neuropeptides 
Citation: Abd El-Aleem SA, Jude EB (2018) Neuropeptides (Substance P) Localisation in the Peripheral Nervous System and Skin in a Diabetic Rat Model: A Possible Mechanism for Acceleration Wound Healing in Diabetic Rats. J Cytol Histol 9: 510. doi: 10.4172/2157-7099.1000510

Page 10 of 12

namely, substance $\mathrm{P}$ has been topically applied to improve wound healing [62,63]. As downregulation of substance $\mathrm{P}$ in diabetic skin is a major contributing factor in the abnormities in healing, we hypothesize that the exogenous application of substance $\mathrm{P}$ could restore nerve integrity and achieve a normal healing.

After establishing the diabetes model in rat and demonstrating the structural and functional neuronal changes, we studied the effect of substance P topical application on the remodelling phase of wound healing. Attention was paid to the remodelling phases and the inflammation resolution phase which start two weeks postwounding. Untreated diabetic wounds showed persistence of inflammation with increased inflammatory cell infiltrate and iNOS expression at the wound site. This delayed inflammatory response caused by the delayed inflammatory cell migration to the wound site [64]. In diabetic wound, macrophage showed unusual activities with reduced exocytotic activity [65], and reduce apoptosis [66] leading to accumulation of dead cells at the wound till late time point [67]. The disordered cellular element of the wound is associated with disordered biochemical element with higher expression of pro-inflammatory cytokines and lower expression of anti-inflammatory cytokines [65] adding to the persistence of inflammation. Substance P deficiency in diabetic wound cause delay inflammatory response which is essential for wound progression [68]. Instead inflammation persists till late time points and impair the healing. Therefore, the cytological and histochemical features seen in the two weeks diabetic wounds are attributed to the delay in inflammation onset and the delay in the resolution [68].

\section{Substance P improved wound healing}

Substance P topical application to the diabetic wounds remarkably improved the healing. By two weeks there was wound contraction/ closure, resolution of inflammation as seen by reduction in inflammatory cell infiltrate and wound iNOS expression. Therefore, substance $\mathrm{P}$ application to the wound restores the normal healing pathway by promoting early inflammatory response and resolution [69]. We have shown here that substance $P$ improved the microcirculation by increasing wound vascularity. This could promote peripheral nerve regeneration [70-74]. Indeed, increasing wound vascularity and nerve regeneration are important factors for diabetic wound healing which enhance cell migration to the wound site. Moreover, increasing wound vascularity would increase inflammatory cell circulation and clear the wound from the accumulated dead macrophage [65-67] with enhancement of exocytosis and apoptosis to clear the wound site for proper healing. This account for our observation where we have shown accumulated macrophages at wound site. Additionally, substance $\mathrm{P}$ affect the proliferative activities of cells at the wound site; keratinocytes proliferation [75,76] would result in reepithelialisation with early wound closure, fibroblast proliferation [77-79] could account for the improvement in collagen deposition and scar formation and endothelial proliferation [80-83] increasing wound angiogenesis. Additionally, substance P accelerates epidermal stem cell migration which promotes wound healing [79-84]. Therefore, substance P promotes important events for the healing such as reepithelialisation, collagen deposition, angiogenesis and cell migration. Substance P enhanced early wound closure this would be the major factor in getting the good postwounding scars. Closure of the wound minimises the infection and the associated tissue damage. Substance $\mathrm{P}$ through enhancing fibroblast migration, proliferation and collagen deposition [77-79] could be a major contributing factor in getting wound contraction and the achievement of the narrow good quality scar.
In conclusion, diabetic patient might benefit from the local application of substance to acute incisional injuries resulting from traumatic or surgical wounds. In addition to the achievement of early wound closure this would also improve the post-wounding scar.

\section{References}

1. Guest JF, Ayoub N, McIlwraith T (2015) Health economic burden that wounds impose on the National Health Service in the UK. BMJ Open 5: e009283.

2. Kerr M (2017) Foot care in diabetes, the human and financial cost. Insight Health Economics.

3. Prompers L, Schaper N, Apelqvist J, Edmonds M, Jude E, et al. (2008) Prediction of outcome in individuals with diabetic foot ulcers: focus on the differences between individuals with and without peripheral arterial disease. The eurodiale E Study 51: 747-755.

4. Mccallion C, Ferguson MWJ (1997) Scar-free embryonic wound healing and the prevention of scarring following wound healing in the adult. Joirrnal of eorrtrcol Medicitze 1: 1-11.

5. Clark RA, Henson PM (1988) Overview and general consideration of wound repair. In: Clark RAF, Henson PM (ed.) The molecular and cellular biology of wound repair. Plenum Press, New York and London, pp: 3-22.

6. Gonzalez AC de O, Costa TF, Andrade Z de A, Medrado ARAP (2016) Wound healing - A literature review. Anais Brasileiros de Dermatologia 91: 614-620.

7. Gurtner GC, Werner S, Barrandon Y, Longaker MT (2008) Wound repair and regeneration. Nature 453: 314-321.

8. Eming SA, Krieg T, Davidson JM (2007) Inflammation in wound repair: molecular and cellular mechanisms. Journal of Investigative Dermatology 127: 514-525.

9. Henry G, Garner WL (2003) Inflammatory mediators in wound healing. Surg Clin North America 83: 483-507.

10. Brem H, Tomic-Canic M (2007) Cellular and molecular basis of wound healing in diabetes. J Clin Invest 117: 1219-1222.

11. Braiman-Wiksman L, Solomonik I, Spira R, Tennenbaum T (2007) Novel Insights into Wound Healing Sequence of Events. Toxico Path 35: 767-779.

12. Kondo T, Ishida Y (2010) Molecular pathology of wound healingMolecular pathology of wound healing. Forens Sci Internat 203: 93-98.

13. Wollina $U$ (1992) The effect of neuropeptides on wound healing in vitro and in vivo. Hautarzt 43: 616-620.

14. Angel VD, McManus AT, Chambers JP (2005) Exogenous administration of substance p enhances wound healing in a novel skin-injury model. Exp Biol Med 230: 271-280.

15. Brain SD (1997) Sensory neuropeptides: their role in inflammation and wound healing. Immunopharmacol 37: 133-152.

16. Suva S (2017) Role of substance p neuropeptide in inflammation, wound healing, and tissue homeostasis. J Immunol 199: 1543-1552.

17. Nabzdyk LP, Kuchibhotla S, Guthrie P, Chun M, Michael A, et al. (2013) Expression of neuropeptides and cytokines in a rabbit model of diabetic neuroischemic wound healing. J Vasc Surg 58: 766-775.

18. Ishikawa S, Takeda A, Akimoto M, Kounoike N, Uchinuma E, et al. (2013) Effects of neuropeptides and their local administration to cutaneous wounds in sensory-impaired areas. J Plast Surg and Hand Sur 48: 143-147.

19. Edmonds ME, Foster AV (2006) Diabetic foot ulcers. BMJ 332: 407-410.

20. Rathur HM, Boulton AJ (2007) The diabetic foot. Clin Dermatol 25: 109-120.

21. Fiorina P, Pietramaggiori G, Scherer SS, Jurewicz M, Mathews JC, et al. (2010) The mobilization and effect of endogenous bone marrow progenitor cells in diabetic wound healing. Cell Transplant 19: 1369-1381.

22. Guo WY, Wang GJ, Wang P, Chen Q, Tan Y, et al. (2010) Acceleration-2010 of diabetic wound healing by low-dose radiation is 
Citation: Abd El-Aleem SA, Jude EB (2018) Neuropeptides (Substance P) Localisation in the Peripheral Nervous System and Skin in a Diabetic Rat Model: A Possible Mechanism for Acceleration Wound Healing in Diabetic Rats. J Cytol Histol 9: 510. doi: 10.4172/2157-7099.1000510

Page 11 of 12

associated with peripheral mobilization of bone marrow stem cells Radiat Res 174: 467-479.

23. Lembeck F, Tsuchiya M, Nagahisa A (1992) The non-peptide tachykinin antagonist, CP-96,345, is a potent inhibitor of neurogenic inflammation. Br J pharmac 105: 527-530.

24. White DM (1997) Release of substance P from peripheral sensory nerve terminals. J Peripher Nerv Syst 2: 191-201.

25. Kawana S, Liang Z, Nagano M (2006) Role of substance P in stressderived degranulation of dermal mast cells in mice. J Dermatol Sci 42: 47-54.

26. O'Connor TM, O'Connell J, O'Brien DI (2004) The role of substance P in inflammatory disease. J Cell Physiol 201: 167-180.

27. Zachary I, Woll P, Rozengurr E (1987) A role for neuropeptides in the control of cell proliferation. Devl Biol 124: 295-308.

28. Reid TW, Murphy CJ, Iwahas MC, Foster B, Mannis MJ (1993) Stimulation of epithelial cell growth by the Substance P and CGRP. Invest Ophthalmol Vis Sci 52: 476-485.

29. Ashrafi M, Baguneid M, Bayat A (2016) The role of neuromediators and innervation in cutaneous wound healing. Acta Derm Venereol 96: 587-594.

30. Lim JF, Chung E, Son Y (2017) A neuropeptide, Substance-P, directly induces tissue-repairing M2 like macrophages by activating the $\mathrm{PI} 3 \mathrm{~K} / \mathrm{Akt} / \mathrm{mTOR}$ pathway even in the presence of IFN $\gamma$. Scientific Reports volume 7: 9417.

31. Jing C, Han W, Hong-Xing Z (2010) Double-edged effects of neuropeptide substance $\mathrm{P}$ on repair of cutaneous trauma. Wound Rep Reg 18: 319-324.

32. Altun V, Hakvoort TE, van Zuijlen PP, van der Kwast TH, Prens EP (2001) Nerve outgrowth and neuropeptide expression during the remodeling of human bum wound scars: A 7-month follow-up study of 22 patients. Bums 27: 717-722.

33. Gibran NS, Jang YC, Isik FF, Greenhalgh DG, Muffley LA, et al. (2002) Diminished neuropeptide levels contribute to the impaired cutaneous healing response associated with diabetes mellitus. J Surg Res 108: 122-128.

34. Lucília S, Eugénia C, Maria C (2010) Role of neuropeptides in skin inflammation and its involvement in diabetic wound healing. Expert opinion on biolog therapy 10: 1427-1439.

35. Khalil Z, Helme R (1996) Sensory peptides as neuromodulators of wound healing in aged rats. J Gerontol a Bioi Sci Med Sci 51: B354-B36I.

36. Park HJ, Kim S, Hong HS (2016) Substance P promotes diabetic wound healing by modulating inflammation and restoring cellular activity of mesenchymal stem cells. Wound Rep Reg 24: 337-348.

37. Gardiner NJ, Freeman OJ (2016) Chapter five-can diabetic neuropathy be modeled In Vitro? Nigel A (ed.) Calcutt, Paul Fernyhough. International Review of Neurobiology, Academic Press 127: 53-87.

38. Yagihashi S, Mizukami H, Sugimoto K (2011) Mechanism of diabetic neuropathy: Where are we now and where to go? J Diab Invest 2: 18-32.

39. Pradhan L, Cai X, Wu S (2011) Gene expression of proinflammatory cytokines and neuropeptides in diabetic wound healing. J surg res 167: 336-342.

40. Calcutt NA (2002) Potential mechanisms of neuropathic pain in diabetes International Review of Neurobiology, Academic Press 50: 205-228.

41. Said G (2007) Diabetic neuropathy-A review. Nat Clin Pract Neurol 3: 331-340.

42. Fernyhough P, Calcutt NA (2016) An introduction to the history and controversies of the pathogenesis of diabetic neuropathy. Int Rev Neurobiol 127: 115-120.

43. Dunnick CA, Gibran NS, Heimbach DM (1996) Substance P has a role in neurogenic mediation of human bum wound healing. J Bum Care Rehabil 17: 390-396

44. Kishi K, Ohyama K, Satoh H, Kubota Y, Tanaka T, et al. (2006) Mutual dependence of murine fetal cutaneous regeneration and peripheral nerve regeneration. Wound Repair Regen 14: 91-99.
45. Matsuda H, Koyama H, Sato H, Sawada J, Itakura A, et al. (1998) Role of nerve growth factor in cutaneous wound healing: accelerating effects in normal and healing-impaired diabetic mice. J Exp Med 187: 297-306.

46. Sahbaie P, Shi X, Guo TZ, Qiao Y, Yeomans DC, et al. (2009) Role of substance $\mathrm{P}$ signaling in enhanced nociceptive sensitization and local cytokine production after incision. Pain 145: 341-349.

47. Scholzen T, Armstrong CA, Bunnett NW, Luger TA, Olerud JE, (1998) Neuropeptides in the skin: interactions between the neuroendocrine and the skin immune systems. Exp Dermatol 7: 81-96.

48. Scott JR, Tamura RN, Muangman P, Isik FF, Xie C, et al. (2008) Topical substance $\mathrm{P}$ increases inflammatory cell density in genetically diabetic murine wounds. Wound repair and regeneration 16: 529-533.

49. Behjati M, Hashemi M (2009) Application of fibrocytes in the treatment of diabetic foot: as a potential new therapeutic approach. Diab Res Clin Pract 86: 152-153.

50. Li B, Wang JH (2011) Fibroblasts and myofibroblasts in wound healing: force generation and measurement. Journal of tissue viability 20: 108-120.

51. Barnes PJ, Brown MJ, Dollery CT, Fuller RW, Heavey OJ, et al. (1986) Histamine is released from skin by substance $\mathrm{P}$ but does not act as the final vasodilator in the axon reflex. Br J Pharmacol 88: 741-745.

52. Holzer P (1988) Local effector functions of capsaicin-sensitive sensory nerve endings: involvement of tachykinins, calcitonin gene-related peptide and other neuropeptides. Neurosci 24: 739-768.

53. Blakytny R, Jude E (2006) The molecular biology of chronic wounds and delayed healing in diabetes. Diab Med 23: 594-608.

54. Teixeira AS, Andrade SP (1999) Glucose-induced inhibition of angiogenesis in the rat sponge granuloma is prevented by aminoguanidine. Life Sci 64: 655-662.

55. Ascher E, Gade PV, Hingorani A, Puthukkeril S, Kallakuri S, et al. (2001) Thiamine reverses hyperglycemia-induced dysfunction in cultured endothelial cells. Sur 130: 851-858.

56. Russo SJ, Mazei-Robison MS, Ables JL, Nestler EJ (2009) Neurotrophic Factors and Structural Plasticity in Addiction. Neuropharmacol 56: 73-82.

57. Hamdy O, Abou-Elenin K, LoGerfo FW, Horton ES, Veves A (2001) Contribution of nerve axon reflex-related vasodilation to the total skin vasodilation in diabetic patients with and without neuropathy. Diab Care 24: 344-349.

58. Bockers M, Benes P, Bork K (1989) Persistent skin ulcers, mutilations and aero-osteolysis in hereditary sensory and autonomic neuropathy with phospholipid excretion. J Am Acad Dermatol 21: 736-739.

59. Hagen NA, Stevens JC, Michel CJ (1990) Trigeminal sensory neuropathy associated with connective tissue disease. Neurol 40: 891-896.

60. Bainbridge P (2013) Wound healing and the role of fibroblasts. J Wound Care 22: 407-408.

61. Epstein EH (1978) Human skin collagen. Presence of type I and type III at all levels of the dermis. J Biol Chem 253: 1336-1337.

62. Kant V, Gopal A, Kumar D, Bag S, Kurade NP, et al. (2013) Topically applied substance $\mathrm{P}$ enhanced healing of open excision wound in rats. Eur J Pharmacol 715: 345-353.

63. Hong HS, Lee J, Lee E, Kwon YS, Lee E, et al. (2009) A new role of substance $\mathrm{P}$ as an injury-inducible messenger for mobilization of CD29(+) stromal-like cells. Nat Med 15: 425-435.

64. Dangwal S, Stratmann B, Bang C, Lorenzen JM, Kumarswamy K (2015) Impairment of wound healing in patients with type 2 diabetes mellitus influences circulating microrna patterns via inflammatory cytokines. Arterioscler Thromb Vasc Biol 35: 1480-1488.

65. Khanna S, Biswas S, Shang Y, Collard E, Azad A, et al. (2010) Macrophage dysfunction impairs resolution of inflammation in the wounds of diabetic mice. PLoS One 5: 9539.

66. Brown DL, Kao WW, Greenhalgh DG (1997) Apoptosis down-regulates inflammation under the advancing epithelial wound edge: delayed patterns in diabetes and improvement with topical growth factors. Surg 121: 372-380. 
Citation: Abd El-Aleem SA, Jude EB (2018) Neuropeptides (Substance P) Localisation in the Peripheral Nervous System and Skin in a Diabetic Rat Model: A Possible Mechanism for Acceleration Wound Healing in Diabetic Rats. J Cytol Histol 9: 510. doi: 10.4172/2157-7099.1000510

Page 12 of 12

67. Mirza RE, Fang MM, Novak ML, Urao N, Sui A, et al. (2015) Macrophage PPAR gamma and impaired wound healing in type 2 diabetes. J Patho 236: 433-444.

68. Leal EC, Carvalho E, Tellechea A, Kafanas A, Tecilazich F, et al. (2015) Substance $\mathrm{P}$ promotes wound healing in diabetes by modulating inflammation and macrophage phenotype. Am J Pathol 185: 1638-1648.

69. Guo WZ, Lai XN, Wang ZG, Liu YJ, Wang LL (2008) Application of exogenous substance $\mathrm{P}$ in wound healing of skin injury in diabetic rat Chuangshang Waike Zazhi 10: 251-253.

70. Okizaki S, Ito Y, Hosono K, Oba K, Ohkubo H, et al. (2015) Suppressed recruitment of alternatively activated macrophages reduces TGF-betal and impairs wound healing in streptozotocin-induced diabetic mice. Biomed Pharmacother 70: 317-325.

71. Ikeda Y, Takei H, Matsumoto C, Mase A, Yamamoto M, et al. (2007) Administration of substance $\mathrm{P}$ during a primary immune response amplifies the secondary immune response via a long-lasting effect on CD8+ T lymphocytes. Arch Dermatol Res 299: 345-351.

72. Zhong QL, Liu DW, Liu FR, Peng Y, Yu M, et al. (2010) Amniotic membrane loading epidermal stem cells accelerates wound healing in diabetic rats. Zhongguo Zuzhi Gongcheng Yanjiu yu Linchuang Kangfu 14: 6010-6014.

73. Zhu F, Fang X, Liu D (2016) Substance P combined with epidermal stem cells promotes wound healing and nerve regeneration in diabetes mellitus. Neur Reg Res 11: 493-501.

74. Wang Q, Muffley LA, Hall K, Chase M, Gibran NS (2009) Elevated glucose and fatty acid levels impair substance P-induced dermal microvascular endothelial cell migration and proliferation in an agarose gel model system. Shock 32: 491-497.
75. McGovern UB, Jones KT, Sharpe GR (1995) Intracellular calcium as a second messenger following growth stimulation of human keratinocytes. Br J Dermatol 132: 892-896.

76. Tanaka TT, Danno K, Ikai K, Imamura S (1988) Effects of substance P and substance $\mathrm{K}$ on the growth of cultured keratinocytes. J Invest Dermatol 90: 399-440.

77. Kahler CM, Reinisch N, Wiederman CJ (1996) Interaction of substance P with epidermal growth factor and fibroblast growth factor in cyclooxygenase-dependent proliferation of human skin fibroblasts. J Cell Physiol 166: 601-608.

78. Nilsson J, von Euler AM, Dalsgaard CJ (1985) Stimulation of connective tissue cell growth by substance P and substance K. Nature 315: 63.

79. Li JF, Fu XB, Sheng ZY, Sun TZ (2003) Redistribution of epidermal stem cells in wound edge in the process of re-epithelialization. Zhonghua Yixue Zazhi 83: 228-231.

80. Ziche M, Morbidelli L, Pacini M, Geppetti P, Alessandri G, et al. (1990) Substance $\mathrm{P}$ stimulates neovascularization in vivo and proliferation of cultured endothelial cells. Microvasc Res 40: 264-278.

81. Fan TP, Hu DE, Guard S, Gresham GA, Watling KJ (1993) Stimulation of angiogenesis by substance $\mathrm{P}$ and interleukin-I in the rat and its inhibition by NKI or interleukin-I receptor antagonists. Br J Pharmacol 110: 43-49.

82. Namuri S, Fujita T (1978) Stimulatory effects of substance P and nerve growth factor (NGF) on neurite outgrowth in embryonic chick dorsal root ganglia. Neuropharmacol 17: 73-76.

83. Fan TP, Hu DE, Smither RL, Gresham GA (1992) Further studies on angiogenesis in a rat sponge model. EXS 61: 308-314.

84. Hong HS, Son Y (2014) Substance-p-mobilized mesenchymal stem cells accelerate skin wound healing. Tissue Eng Regen Med 11: 483 